\title{
Human clinical experience with adipose precursor cells seeded on hyaluronic acid-based spongy scaffolds
}

\author{
F.B. Stillaert ${ }^{\mathrm{a}, *}$, C. Di Bartolo ${ }^{\mathrm{b}}$, J.A. Hunt ${ }^{\mathrm{c}}$, N.P. Rhodes ${ }^{\mathrm{c}}$, E. Tognana ${ }^{\mathrm{b}}$, S. Monstrey ${ }^{\mathrm{a}}$, P.N. Blondeel ${ }^{\mathrm{a}}$ \\ ${ }^{a}$ Department of Plastic and Reconstructive Surgery, University Hospital Gent, De Pintelaan 185, 9000 Gent, Belgium \\ ${ }^{\mathrm{b}}$ Fidia Advanced Biopolymers s.r.l., Abano Terme, Padova, Italy \\ ${ }^{\mathrm{C}}$ University of Liverpool, UK Centre for Tissue Engineering, Liverpool, United Kingdom
}

\section{A R T I C L E I N F O}

\section{Article history:}

Received 24 March 2008

Accepted 10 June 2008

Available online 17 July 2008

\section{Keywords:}

Adipose tissue engineering

Hyaluronic acid

Scaffold

\begin{abstract}
A B S T R A C T
Histioconductive approaches to soft-tissue defects use scaffolds seeded with lineage- and tissue-specific progenitors to generate tissue which should reside in equilibrium with adjacent tissue. Scaffolds guide histiogenesis by ensuring cell-cell and cell-matrix interactions. Hyaluronic acid-based (HA) preadipocyte-seeded scaffolds were evaluated for their adipo-conductive potential and efficacy in humans. Preadipocytes were isolated from lipoaspirate material and seeded on HA scaffolds. The cellular biohybrid (ADIPOGRAFT ${ }^{\circledR}$ ) and an acellular control scaffold $\left(\right.$ HYAFF $\left.^{\circledR} 11\right)$ were implanted subcutaneously. At specific time points (2, 8 and 16 weeks) explants were analyzed histopathologically with immunohistochemistry. No adverse tissue effects occurred. Volume loss and consistent degradation of the HYAFF ${ }^{\circledR} 11$ scaffolds compared to the ADIPOGRAFT ${ }^{\circledR}$ group indicated progressive tissue integration. No consistent histological differences between both groups were observed. By 8 weeks all void spaces within the scaffolds were filled with cells with pronounced matrix deposition in the ADIPOGRAFT ${ }^{\circledR}$ bio-hybrids. Here we show that HA scaffolds were stable cell carriers and had the potential to generate volumeretaining tissue. However, no adipogenic differentiation was observed within the preadipocyte-seeded scaffolds.
\end{abstract}

(c) 2008 Elsevier Ltd. All rights reserved.

\section{Introduction}

Engineered adipose tissue could overcome the disadvantages associated with the implantation of synthetic materials or autologous soft-tissue grafts. The fascination for adipose tissue as an autologous substitute to approach tissue deficiencies emerges from its intrinsic characteristics. It not only is available in easily accessible subcutaneous depots but is also very manageable in the way tissue defects can be structurally moulded to reconstruct the dimensions of the lost body contour. Adipose tissue is organized into a three-dimensional dynamic connective tissue which hosts a stromal fraction, and a microvascular plexus entwined within a highly organized extracellular matrix (ECM) [1]. This stromalvascular fraction (SVF) consists of a heterogeneous cell population of which the adipose-derived adult stem (ADAS) cells are of significant interest for potential regenerative applications [2]. These multipotent cells [3] can be harvested through liposuction without altering their viability $[4,5]$. The objective in engineering adipose tissue is to shape a three-dimensional tissue substitute which prospers by biochemical, physical, and cellular cues and

\footnotetext{
* Corresponding author.

E-mail address: filip.stillaert@ugent.be (F.B. Stillaert).
}

approximates the native tissue equivalent. Histioconductive tissue engineering strategies use additional materials as cell carriers (scaffolds) to create the shape and dimensions of reparative tissues and then functionally and molecularly integrate those bio-hybrids within the surrounding host tissue. Materials that meet fundamental requirements such as controlled degradation, cytotoxicity and immunogenity are needed. Research reports have shown successful and reproducible inoculation and culturing of adipocyteand preadipocyte-precursor cells (preadipocytes and progenitors, respectively) on synthetic [6,7] or natural [8] prefabricated scaffolds [9] with subsequent differentiation in vitro or adipose tissue formation in vivo [10]. The scaffolds within these bio-hybrids provided the seeded cells specific attachment or binding sites, shaped the tissue construct and functioned as geometrical environments in which not only cells received their essential cues for a structural cell organization and cellular behaviour but also cellular function was modulated [11,12]. Various scaffold materials have been analyzed in experiments for autotransplantation as well as for in vitro or in vivo growth and differentiation of preadipocytes $[6,9,13,14]$ but no data extrapolations have been realized yet to clinical applications. In this pilot clinical trial hyaluronic acid-based (HA) scaffolds $\left(\right.$ HYAFF $\left.^{\circledR} 11\right)$ were used as a cell-carrier material. This naturally occurring polysaccharide is a major component of the ECM in connective tissues [15], plays a prominent role in cellular behaviour 

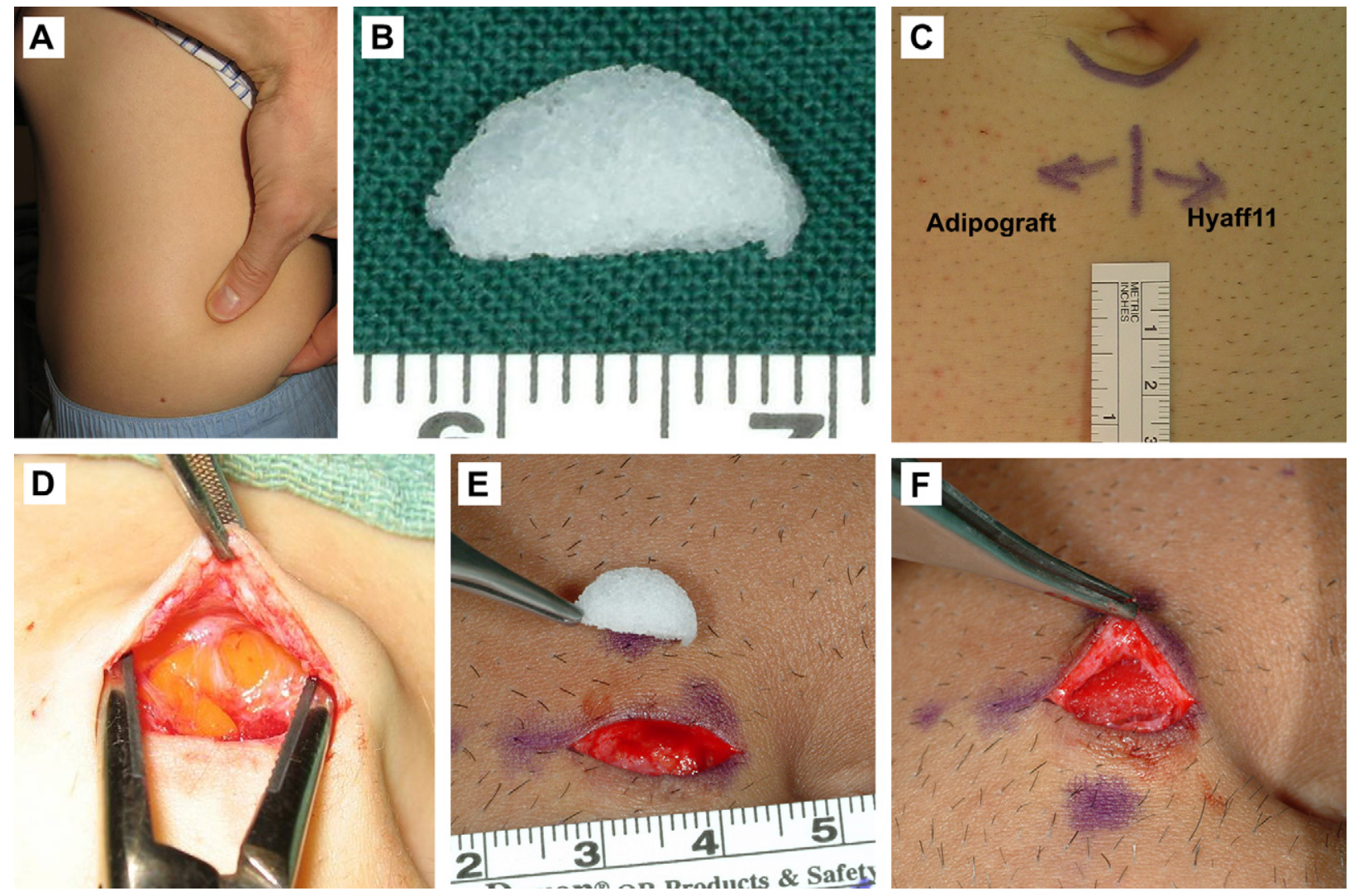

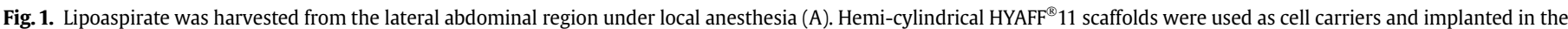

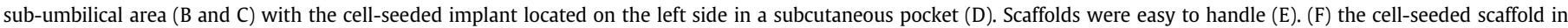
place.

and exerts an important mechanical role [16]. Being a polysaccharide and not a protein it is potentially less antigenic, which is an important property when considering clinical uses. Its supportive role for precursor cell proliferation and differentiation has been confirmed by several in vivo and in vitro studies [17]. HYAFF $^{\circledR} 11$ is based on hyaluronic acid modified by esterification which increases the hydrophobicity, the residence time in vivo and makes it more resistant to hyaluronidase activity. Previous studies observed the potential to support expansion and differentiation of adipose precursor cells in vivo [8]. When implanted in nude mice human preadipocyte-seeded HYAFF $^{\circledR} 11$ sponges showed a higher cell density than collagen constructs after 3 weeks [10]. Halbleib et al. defined the experimental conditions under which human adipocyte precursor cells could be effectively inoculated and cultured on HA scaffolds [9] and provided basic evidence that human preadipocytes can be used to establish adipose tissue engineering techniques to obtain a three-dimensional soft-tissue filler. Their appropriate and well-defined porous microarchitecture not only allows morphogenesis but also provides an environment for matrix deposition and angiogenesis. Based on these promising findings and the straightforward clinical flowchart a clinical trial was setup to evaluate the efficiency of those scaffolds in humans in vivo, mimicking a clinical small-volume tissue deficit.

\section{Materials and methods}

\subsection{Lipoaspirate material}

All experimental procedures were approved by the Human Research Ethics Committee. Twelve volunteers, aged 20-35 years, were included in this trial according to specific inclusion criteria (average age $=25.5$; average $\mathrm{BMI}=23.5$ ). Lipoaspirate material was obtained ( $\sim 5$ to $10 \mathrm{cc}$ ) through a liposuction procedure under local anaesthesia (Xylocain $1 \%$ without adrenalin) with informed consent through the Department of Plastic Surgery of the University Hospital Gent. Lipoaspirate material was aspirated through a Coleman ASP I $(\varnothing=2.5 \mathrm{~mm})$ liposuction cannula connected to a $10 \mathrm{cc}$ sterile luer-lock disposable syringe. The average aspirated fat volume per volunteer was $8.27 \mathrm{cc}$. Donor sites were the lower lateral abdominal areas in all cases (Fig. 1A). The sealed luer-lock syringes containing the lipoaspirate were stored in a cooled foamy kit.

\subsection{Isolation of human adipose stromal cells}

The fat tissue samples were immediately dispatched to Fidia Advanced Biopolymers (FAB) Laboratories (Abano Terme, Italy) for further processing. All samples arrived within $24 \mathrm{~h}$. Lipoaspirate material was washed three times with PBS (vol:vol, $1: 1$ ) and digested at $37^{\circ} \mathrm{C}$ with a sterile filtered collagenase solution (collagenase Type I $500 \mathrm{U} / \mathrm{ml}, 8 \%$ FCS, 0.02 м HEPES and $0.02 \mathrm{IU}-0.02 \mathrm{mg} / \mathrm{ml}$ penicillin/streptomycin in Dulbecco's modified eagle medium/Ham's F-12) (vol:vol, 1:1) for 1 h. Prior experiments have demonstrated a cell concentration recovery of 0.15 $0.2 \times 10^{6}$ cells/cc of fat after collagenase digestion. The yield of preadipocyte cells from $1 \mathrm{~g}$ adipose tissue was in the range of $2-3 \times 10^{5}$ cells of which not more than $78 \%$ attached to the scaffolds [9]. As $5-8 \mathrm{ml}$ of lipoaspirate was digested, the number of cells recovered was in the range of $0.75-1.6 \times 10^{6}$. After centrifugation $(200 \mathrm{~g}$ for $10 \mathrm{~min}$ at $17^{\circ} \mathrm{C}$ ) and removal of the supernatant, cells were resuspended in a preadipocyte culture medium (DMEM/Ham's F-12 supplemented with $10 \% \mathrm{FCS}, 1 \mathrm{~nm}$ basic fibroblast growth factor (bFGF), $0.02 \mathrm{IU}-0.02 \mathrm{mg} / \mathrm{ml}$ penicillin/streptomycin) to obtain a final volume of $\sim 100$ to $200 \mu$ l. Cells isolated by all samples differentiated into mature adipocytes after 1 week of culture in differentiation medium.

\subsection{Characteristics of the scaffolds}

HYAFF $^{\circledR} 11$ scaffolds were provided by Fidia Advanced Biopolymers s.r.l. (FAB, Abano, Italy) (Fig. 1B). HYAFF ${ }^{\circledR} 11$ is a linear derivative of hyaluronic acid modified by complete esterification of the carboxylic function of glucuronic acid with benzyl groups [18]. HYAFF ${ }^{\circledR} 11$ biomaterial is spontaneously degraded and resorbed. The structure of the sponges used in this trial showed open, interconnecting pores with pore size of $400 \mu \mathrm{m}$. HYAFF $^{\circledR} 11$ sponges with a pore size of $400 \mu \mathrm{m}$ appeared to be superior to other scaffold types regarding cell attachment rate [9]. HYAFF $^{\circledR} 11$ scaffolds were prepared as semi-cylindrical disks with a diameter of $10 \mathrm{~mm}$ and a height of $4 \mathrm{~mm}$ and were sterilized by $\gamma$-radiation. 

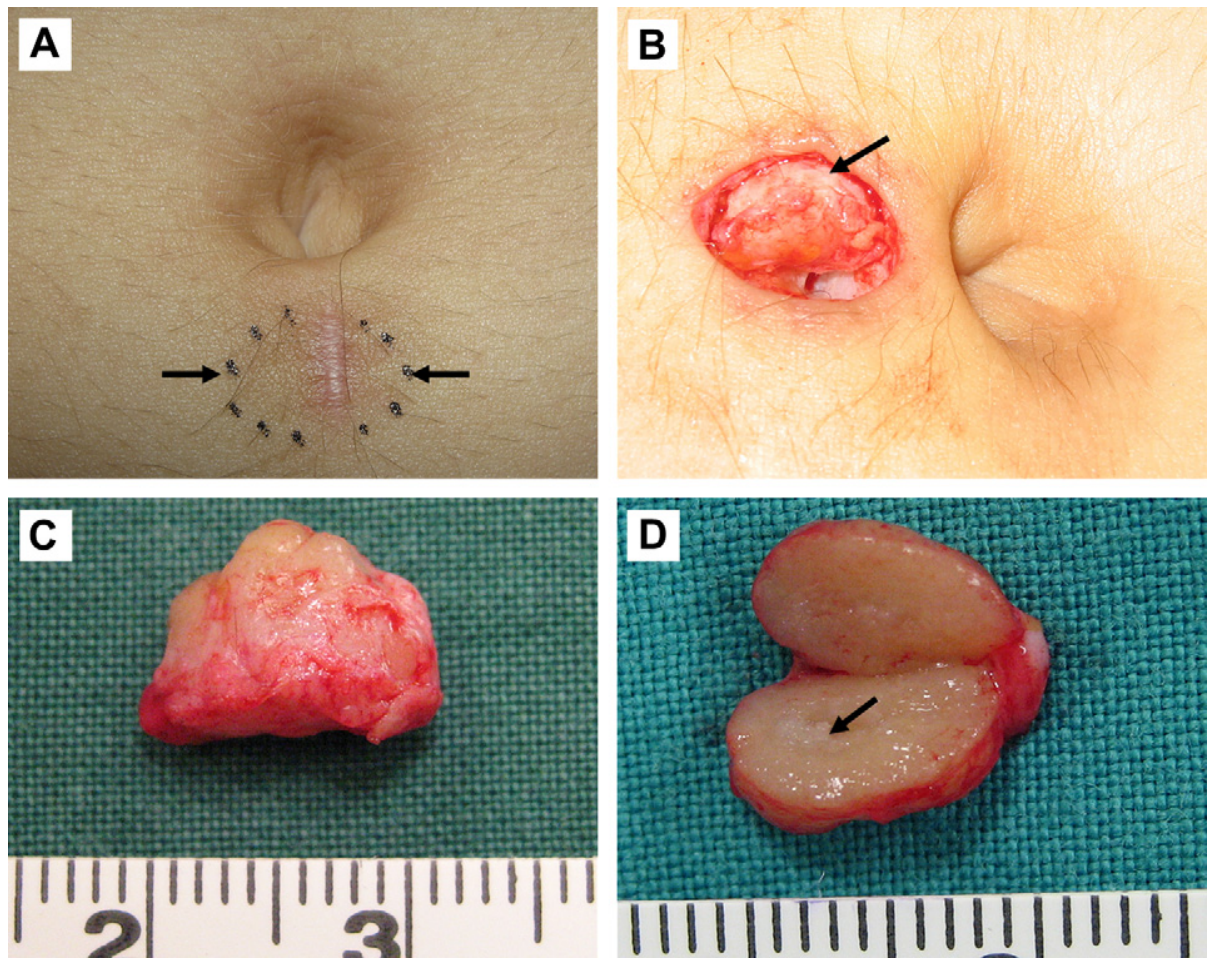

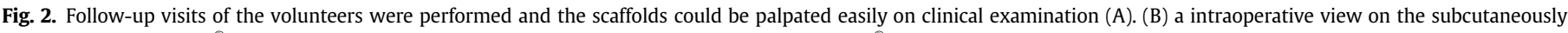

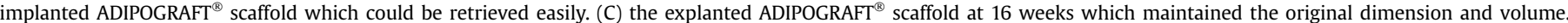

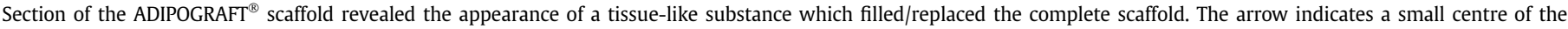
scaffold with the absence of the tissue-like substance in which part of the hyaluronic acid material could be retrieved.

\subsection{Scaffold preparation}

The hemi-cylindrical HYAFF ${ }^{\circledR} 11$ sponges were hydrated for $24 \mathrm{~h}$ at $37^{\circ} \mathrm{C}$ in an atmosphere of $5 \% \mathrm{CO}_{2}$ and $95 \%$ humidity. Sponges were then washed three times with $10 \mathrm{ml}$ of DMEM/Ham's F-12 medium supplemented with $10 \%$ FCS. Sponges were finally dried out using a disposable pipette connected to vacuum [19].

\subsection{Cell inoculation of the scaffolds}

Cell seeding was performed by moving the cell-suspension containing pipette across the entire surface of the sponge [9]. Considering a $10 \%$ cell loss during the seeding procedure (evaluated during experiments on cell seeding efficiency), the number of cells seeded on each semi-cylindrical ADIPOGRAFT ${ }^{\circledR}$ scaffold ranged between $0.67 \times 10^{6}$ and $1.4 \times 10^{6}$. The cell-seeded hemi-cylindrical HYAFF $^{\circledR} 11$ sponge was called ADIPOGRAFT ${ }^{\circledR}$. Seeded and non-seeded HYAFF ${ }^{\circledR} 11$ sponges were incubated and supplied with a preadipocyte culture medium $3 \mathrm{~h}$ after incubation with fresh medium changed (DMEM/Ham's F-12 medium supplemented with $10 \%$ FCS) after $24 \mathrm{~h}$. Sponges were washed three times with sterile phosphate buffered saline $48 \mathrm{~h}$ later and stored in an appropriate vacuum sealed double sterile package ready for transport. Before packaging a LAL test was performed on the medium submerging the sponges to check for bacterial endotoxins.

\subsection{Implantation and flowchart}

Four days after the initial liposuction the ADIPOGRAFT ${ }^{\circledR}$ bio-hybrid and an acellular control HYAFF ${ }^{\circledR} 11$ scaffold were implanted under local anaesthesia (Xylocain $1 \%$ without adrenalin) (Fig. 1C-F). The skin was disinfected with chlorhexidin aqua $0.5 \%$ (pharmacy UZ Gent). Through a $1 \mathrm{~cm}$ median sub-umbilical skin incision two paramedian subcutaneous pockets were created by blunt dissection $(1.5 \mathrm{~cm}$ by $1 \mathrm{~cm}$ ) (Fig. 1). Seeded and non-seeded sponges were unpacked and immediately implanted taking care to avoid any trauma to their fragile consistency. Implants were not weighed before implantation. The ADIPOGRAFT ${ }^{\circledR}$ bio-hybrid was implanted in the right subcutaneous pocket while the control HYAFF ${ }^{\circledR} 11$ scaffold was positioned in the left subcutaneous pocket (Fig. 2). The incision was closed with subdermal sterile absorbable subcutaneous 5-0 sutures (Ethicon ${ }^{\circledR}$ ) and a running intracuticular non-resorbable 6-0 suture $\left(\right.$ Ethicon $^{\circledR}$ ).

\subsection{Time courses, follow-up and harvest}

Three time courses (2 (T1), 8 (T2) and 16 (T3) weeks) were conducted for each group consisting of four volunteers which were followed on a weekly outpatient basis. In the 16 weeks' group one volunteer ultimately decided not to be included in the trial. He was not replaced as the recruitment process was already finalized. At the specific time points the tissue specimens were harvested under local anaesthesia through the same initial incision (Fig. 3). Careful dissection excised a margin of surrounding fat tissue to ensure complete removal of the scaffolds which were easily identified intraoperatively. Specimens were not weighed due to the presence of a variable amount of native and fibrotic tissue which could interfere with the final weight. The harvested tissue specimens were embedded in phosphate buffered saline. Thin sections $(4 \mu \mathrm{m})$ were cut using polycut sectioning. Sections were stained with haematoxylin and eosin, Van Geison viewed by light microscopy (Zeiss).

\section{Results}

\subsection{Clinical follow-up}

All surgical procedures were completely successful and uneventful and during the entire postoperative follow-up there were no adverse effects observed with the implants, both for cell-seeded and unseeded scaffolds. Implantation sites in all experimental groups showed no signs of wound dehiscence, scar contracture or scaffold migration. Scaffolds were not visible at clinical inspection but clinical examination revealed palpable margins of all cellseeded scaffolds in all groups and the T1 control group ( 2 weeks) (Fig. 2A). HYAFF $^{\circledR} 11$ control scaffolds in T2 and T3 were non-palpable indicating progressive scaffold degradation. This is consistent with findings of other investigators [19]. However, during followup the overlying subdermal and dermal tissues showed no depression with good preserved skin quality in all groups. The scaffolds in the cell-seeded group felt moderately soft while non-seeded scaffolds in general appeared to disintegrate during follow-up, in particular in the 8 and 16 weeks' group.

\subsection{Macroscopy}

At the selected time points the scaffolds were harvested from the subcutaneous pouches in the infra-umbilical area. Fig. 2B 

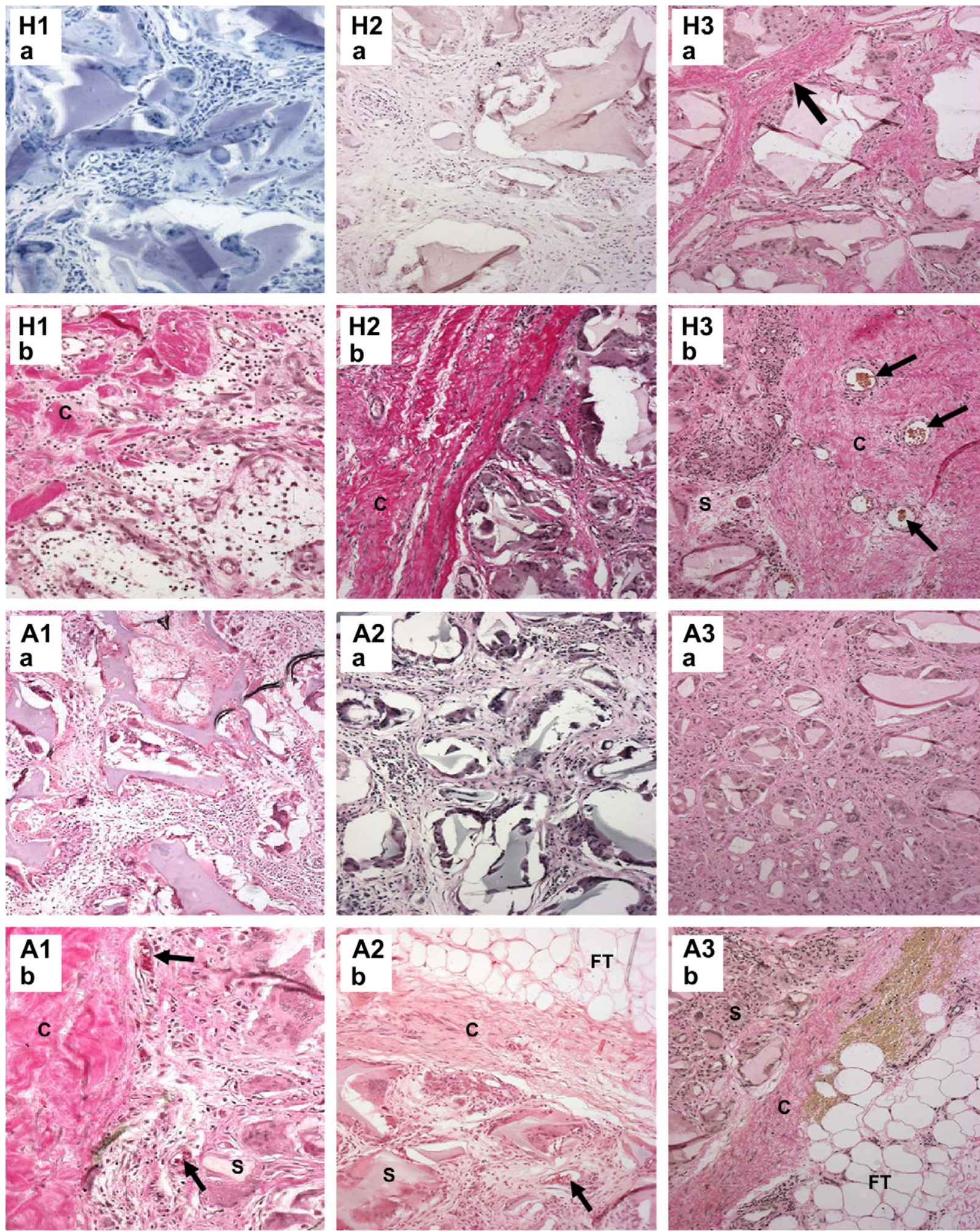

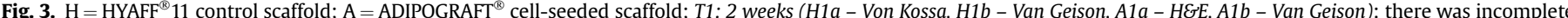

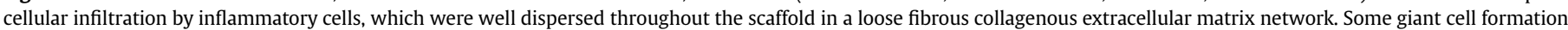

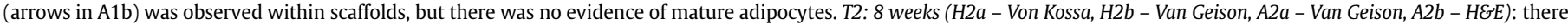

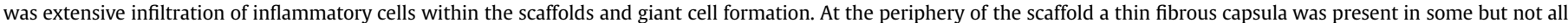

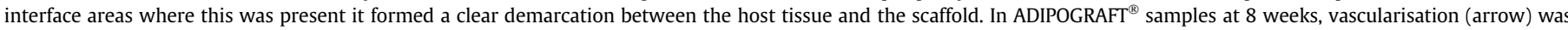

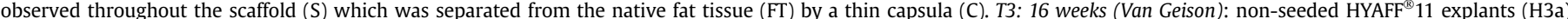

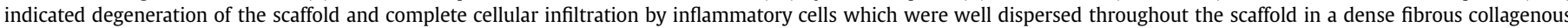

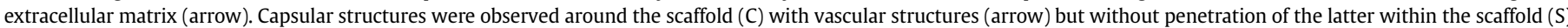

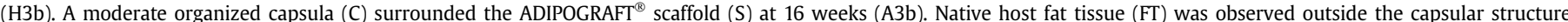

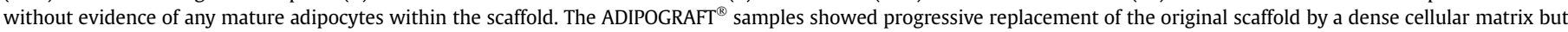
without evidence of the presence of mature adipocytes. Pore size decreased dramatically within this group. 
demonstrates the retrieval process of the ADIPOGRAFT ${ }^{\circledR}$ scaffold. Note the thin capsule formation around the scaffold with good integration in the surrounding host tissue. The volume of the scaffold was maintained with the diameter being $10 \mathrm{~mm}$, as originally fabricated (Fig. 2C). A cross-section of the engineered tissue construct revealed a pale appearance of the tissue within the scaffold (Fig. 2D). All ADIPOGRAFT ${ }^{\circledR}$ scaffolds were retrieved easily in each time group and maintained their original shape and dimension. Interestingly, the $\mathrm{HYAFF}^{\circledR} 11$ explants showed consistent volume loss with degradation of the scaffold into a "gel-like" substance, in particular in the 8 (T2) and 16 (T3) weeks' group. In the 16 weeks' group two $\mathrm{HYAFF}^{\circledR} 11$ scaffolds were not detectable at harvest. Thus, macroscopic examination qualitatively revealed that cell-seeded scaffolds contributed to the shape and dimension maintenance of the bio-hybrids.

The representative ADIPOGRAFT ${ }^{\circledR}$ scaffolds not only maintained their original volume and dimension but also demonstrated the presence of a tissue-like substance within the scaffold, suggesting that a substantial amount of extracellular matrix or adipose-like tissue had been synthesized in the cell-seeded scaffolds. Quantification of the diameters of in vivo harvested ADIPOGRAFT ${ }^{\circledR}$ and HYAFF $^{\circledR} 11$ scaffolds confirmed that the latter shrunk and almost completely lost their original dimensions. Cell-seeded scaffolds were significantly bigger than corresponding acellular scaffolds.

\subsection{Histological features}

Cell-free scaffolds stained with haematoxylin and eosin, Von Kossa and Van Geison demonstrated the invasion of cells within the scaffold (Fig. 3). Cell infiltration was initially incomplete at 2 weeks. HYAFF $^{\circledR} 11$ scaffolds demonstrated both cell dense and cell sparse areas in an intact scaffold matrix (Fig. 3, H1a). There was no evidence of mature adipocytes present within or at the periphery of the HYAFF $^{\circledR} 11$ scaffold in all groups. By 8 weeks all void spaces were filled with cells or extracellular matrix. At 16 weeks the control scaffolds showed the replacement of the $\mathrm{HYAFF}^{\circledR} 11$ material by a significant and dense fibrous collagenous ECM network (Fig. 3, H3a) with scaffold material still intact. Over time, the overall pore size diameter decreased significantly due to the increasing deposition of a dense interconnecting ECM and the population of inflammatory cells becoming well established throughout the scaffold. Few vascular structures and no calcification were observed within the acellular scaffolds. Capsula formation was observed which became well vascularised at 16 weeks (Fig. 3, H3b). Despite a well developed vascular plexus within the fibrotic capsula there seemed to be little or no neo-vessel formation at the periphery or within the non-seeded scaffold. ADIPOGRAFT ${ }^{\circledR}$ explants stained with haematoxylin and eosin, Von Kossa and Van Geison demonstrated increased collagen deposition compared to the control scaffolds (Fig. 3, A3a). An incomplete cellular population was observed with cells well dispersed throughout the scaffold but in greater numbers compared to the $\operatorname{HYAFF}^{\circledR} 11$ control scaffolds. There was an increase in inflammatory granulation in some areas within the scaffold which were still maintained in a fibrous extracellular matrix network. Margins and significant areas inside scaffold demonstrated inflammatory cell infiltration. In ADIPOGRAFT ${ }^{\circledR}$ explants at 2 and 8 weeks vascular structures (Fig. 3, A1b and A2b) were noticeable at the periphery of the scaffold. Few vascular structures were observed in the deeper layers of the ADIPOGRAFT ${ }^{\circledR}$ samples. There was a discrete capsula formation (Fig. 3, A2b and A3b) which distinctively separated the scaffold from the surrounding native fat tissue. The original scaffold within this group underwent an increased rate of degradation compared to the nonseeded group. Despite some distinctive differences between the experimental and control groups no mature adipocytes were indicated within the ADIPOGRAFT ${ }^{\circledR}$ explants. Cellularity was higher in all cell-loaded scaffolds compared to the non-seeded control groups. Pore diameters differed after 8 weeks of implantation with a continuous decrease in pore size which was prominent in the 16 weeks cell-loaded group.

\section{Discussion}

A tissue engineering approach that uses implantable preadipocyte-seeded natural or synthetic polymer scaffolds should result in a living adipo-inductive substitute, which could overcome current disadvantages of autograft and allogenic volume substitutes. The availability of progenitors within the adipose stromal fraction for building desired neo-tissue types and the understanding of vectors that govern their differentiation emerge as important factors for successful neo-tissue construction [20]. Tissue engineering research uses regenerative protocols that involve the engineered recapitulation of certain embryonic events [21] that coordinate the morphogenesis of the targeted tissue. The extracellular matrix (ECM) is recognized as a highly hydrated network which comprises several main effectors [22-24]. Its architecture provides not only an instructive cue for the conversion and spatial orientation [25] of precursor cells into a functional tissue [26] but also properties at a macroscale level provide a number of tissue functions including osmosis, molecular and nutrient transport $[12,27]$. A central event in adipogenesis is the active remodelling of the ECM [28]. Biodegradable scaffolds designed to meet tissue engineering purposes mimic the in vivo three-dimensional extracellular microarchitecture to provide precursors the signals to develop in desirable phenotypes, the means for cell expansion and the space for the newly deposited ECM to achieve properties similar to those of the native tissue [1,29]. Scaffolds have been widely used for regenerating tissues $[15,30]$. The open, porous structure acts as a preserver of space for efficient cellular adhesion and seeding and facilitates vessel ingrowth with subsequent mass transport of oxygen and nutrients. The three-dimensional geometry of the native ECM constrains cells during regeneration and provides space for tissue development [25] and in vitro studies have shown that the scaffold geometry promotes preadipocyte differentiation [31]. The architecture of adipose tissue has been reconstructed using adipose-derived stromal cells seeded onto different scaffold materials $[6-8,13,14]$. Hyaluronic acid-based scaffolds have been used clinically to successfully direct chondrocyte development [32-34]. The nonantigenic hyaluronic acid molecule is a prominent interstitial protein in the ECM. It plays a prominent role in cellular function and behaviour, tissue viscosity and osmosis and fulfils an important mechanical role in shock absorption and space filling [35-37]. Previous studies showed that $\operatorname{HYAFF}^{\circledR} 11$ scaffolds with a pore size diameter of $400 \mu \mathrm{m}$ were suitable environments for adipocyte precursor cell seeding with subsequent proliferation and differentiation [9]. Controlled or predictable scaffold resorption is a crucial requirement when considering histioconductive approaches for organogenesis. Besides a good initial mechanical stability the acellular HYAFF ${ }^{\circledR} 11$ scaffolds in this trial showed a progressive degradation rate with pore size reduction over time with a gradual deposition of a newly formed ECM. The non-inflammatory defragmentation process resulted in the formation of a gel-like substance noted macroscopically at harvest. Two HYAFF ${ }^{\circledR} 11$ scaffolds were completely disintegrated at 16 weeks. They lacked cytotoxicity and promoted the invasion of an aspecific cell population with no elicitation of an immune or inflammatory response indicating their compatibility with the physiological host conditions [16]. The gross shape and volume of the cellular ADIPOGRAFT ${ }^{\circledR}$ scaffolds were maintained indicating that HA scaffolds do have the potential to act as anchor sites and preservers of space for cells to develop into multicellular communities which resulted in the 
synchronous integration of the bio-hybrid within adjacent tissues. Cellularity with pronounced ECM deposition was higher in all cellloaded scaffolds compared to the non-seeded control groups consistent with previous findings in rodents [19]. This finding was prominent from 8 weeks on and increased in the 16 weeks' group. In contrast to previous findings in rodents, no differentiated adipocytes were observed within the sponges. Organogenesis requires a fortiori the presence of a functional vascular network and the disadvantage of cell-based tissue engineering strategies is that the seeded cell population in implanted bio-hybrids will be located more than $100 \mu \mathrm{m}$ away from the native microvasculature which is the diffusion limit for oxygen. Migration and proliferation of quiescent endothelial cells from pre-existing vessels - a process called angiogenesis [38] - will only occur in a later stage to establish a nourishing vascular plexus. A xenograft study showed that human preadipocyte-seeded HA scaffolds were indeed revascularized with integrated vessels in almost all layers of the sponge with preadipocytes being well distributed over the cross-section of the implanted sponge [19]. Despite the fact that oligomers, the degradation fragments of hyaluronic acid, act on angiogenesis [39] and that preadipocytes have a lower oxygen consumption and higher tolerance for survival than mature fat cells [40] the major disadvantage of cell-based strategies is that the pre-cultured tissue constructs, which must become vascularised once implanted within the recipient, may not be as successful as methods which foster a primary neovascularisation of a biological matrix or scaffold [41]. Embryological adipose tissue formation is preceded by the establishment of a primary vascular plexus, also called the "primitive fat organ", and further development of adult adipose tissue is associated with a concomitant increase in the microcirculatory network. It shows how the interplay between adipocytes and their vascular compartment characterizes its homeostatic dynamism. In this human trial, no neo-capillary in-growth was observed within the cellular or acellular sponges.

\section{Conclusion}

Hyaluronic acid-based scaffolds were demonstrated to be suitable materials for soft-tissue regeneration; they maintained volume when seeded with preadipocytes. The material had a progressive rate of biodegradation, lacked cytotoxicity and did not induce a systemic immune response or chronic inflammation in this human in vivo model. Although various materials have been tested for the potential construction of adipo-scaffolds, major challenges remain in facilitating adipogenic cell attachment, migration, and formation of natural adipose matrix in three-dimensional biomaterials. Despite promising results in rodents and excellent biocompatibility and degradation characteristics, HA scaffolds do not support preadipocyte survival and are not inductive towards adipose tissue formation. The observed volume maintenance and tissue integration are promising but the deficient angiogenic penetration which may compromise further tissue stabilisation requires further development to assess whether this histioconductive strategy can be used in future soft-tissue augmentation procedures.

\section{Acknowledgements}

We wish to thank the nursing staff of the Department of Plastic Surgery UZ Gent, for their assistance during the surgical procedures and clinical follow-up. This project was funded by the European Community under the Growth Programme (Vth framework programme) (G5RD-CT-1999-00111, Number GRD1-1999-11159).

\section{References}

[1] Langer R, Vacanti JP. Tissue engineering. Science 1993;260(5110):920-6.

[2] Gimble JM, Katz AJ, Bunnell BA. Adipose-derived stem cells for regenerative medicine. Circ Res 2007;100(9):1249-60.

[3] Gimble JM, Guilak F. Differentiation potential of adipose derived adult stem (ADAS) cells. Curr Top Dev Biol 2003;58:137-60.

[4] Moore Jr JH, Kolaczynski JW, Morales LM, Considine RV, Pietrzkowski Z, Noto PF, et al. Viability of fat obtained by syringe suction lipectomy: effects of local anesthesia with lidocaine. Aesthetic Plast Surg 1995;19(4):335-9.

[5] Lalikos JF, Li YQ, Roth TP, Doyle JW, Matory WE, Lawrence WT. Biochemical assessment of cellular damage after adipocyte harvest. J Surg Res 1997;70(1): 95-100.

[6] Patrick CW, Chauvin PB, Hobley J, Reece GP. Preadipocyte seeded PLGA scaffolds for adipose tissue engineering. Tissue Eng 1999;5(2):139-51.

[7] Patrick CW, Zheng B, Johnston C, Reece GP. Long-term implantation of preadipocyte-seeded PLGA scaffolds. Tissue Eng 2002;8(2):283-93.

[8] von Heimburgh D, Zachariah S, Heschel I, Kuhling H, Schoof H, Hafemann B, et al. Human preadipocytes seeded on freeze-dried collagen scaffolds investigated in vitro and in vivo. Biomaterials 2001;22(5):429-38.

[9] Halbleib M, Skurk T, de Luca C, von Heimburg D, Hauner H. Tissue engineering of white adipose tissue using hyaluronic acid-based scaffolds. I: in vitro differentiation of human adipocyte precursor cells on scaffolds. Biomaterials 2003;24(18):3125-32.

10] von Heimburg D, Zachariah S, Low A, Pallua N. Influence of different biodegradable carriers on the in vivo behavior of human adipose precursor cells. Plast Reconstr Surg 2001;108(2):411-20. Discussion 421-2.

[11] Chen CS, Mrksich M, Huang S, Whitesides GM, Ingber DE. Geometric control of cell life and death. Science 1997;276(5317):1425-8.

[12] Atala A. Tissue engineering of artificial organs. J Endourol 2000;14(1):49-57.

[13] Kral JG, Crandall DL. Development of a human adipocyte synthetic polymer scaffold. Plast Reconstr Surg 1999;104(6):1732-8.

[14] Huss FR, Kratz G. Mammary epithelial cell and adipocyte co-culture in a 3-D matrix: the first step towards tissue-engineered human breast tissue. Cells Tissues Organs 2001;169(4):361-7.

[15] Yoo HS, Lee EA, Yoon JJ, Park TG. Hyaluronic acid modified biodegradable scaffolds for cartilage tissue engineering. Biomaterials 2005;26(14):192533.

[16] Gray SD, Titze IR, Chan R, Hammond TH. Vocal fold proteoglycans and their influence on biomechanics. Laryngoscope 1999;109(6):845-54.

[17] Solchaga LA, Dennis JE, Goldberg VM, Caplan AI. Hyaluronic acid-based polymers as cell carriers for tissue-engineered repair of bone and cartilage. J Orthop Res 1999;17(2):205-13.

[18] Campoccia D, Hunt JA, Doherty PJ, Zhong SP, O'Regan M, Benedetti L, et al Quantitative assessment of the tissue-response to films of hyaluronan derivatives. Biomaterials 1996;17(10):963-75.

[19] Hemmrich K, von Heimburg D, Rendchen R, Di Bartolo C, Milella E, Pallua N Implantation of preadipocyte-loaded hyaluronic acid-based scaffolds into nude mice to evaluate potential for soft tissue engineering. Biomaterials 2005 ; 26(34):7025-37.

[20] Zuk PA, Zhu M, Ashjian P, De Ugarte DA, Huang JI, Mizuno H, et al. Human adipose tissue is a source of multipotent stem cells. Mol Biol Cell 2002;13(12): 4279-95.

[21] Caplan AI. Embryonic development and the principles of tissue engineering. Novartis Found Symp 2003;249:17-25. Discussion 25-33, 170-4, 239-41.

22] Crandall DL, Hausman GJ, Kral JG. A review of the microcirculation of adipose tissue: anatomic, metabolic, and angiogenic perspectives. Microcirculation $1997 ; 4(2): 211-32$

[23] Gray SD, Titze IR, Alipour F, Hammond TH. Biochemical and histologic observations of vocal fold fibrous proteins. Ann Otol Rhinol Laryngol 2000; 109(1):77-85

[24] Pawlak AS, Hammond T, Hammond E, Gray SD. Immunocytochemical study of proteoglycans in vocal folds. Ann Otol Rhinol Laryngol 1996;105(1):6-11.

[25] Tsang VL, Bhatia SN. Three-dimensional tissue fabrication. Adv Drug Deliv Rev 2004;56(11):1635-47.

[26] Nakajima I, Yamaguchi T, Ozutsumi K, Aso H. Adipose tissue extracellular matrix: newly organized by adipocytes during differentiation. Differentiation 1998;63(4):193-200.

[27] Hutmacher DW. Scaffolds in tissue engineering bone and cartilage. Biomaterials 2000;21:2529-43.

[28] Li Y, Ma T, Kniss DA, Lasky LC, Yang ST. Effects of filtration seeding on cell density, spatial distribution, and proliferation in nonwoven fibrous matrices. Biotechnol Prog 2001;17(5):935-44.

[29] Li Y, Yang ST. Effects of three-dimensional scaffolds on cell organization and tissue development. Biotechnol Bioprocess Eng 2001;6:311.

[30] Kaufmann PM, Heimrath S, Kim BS, Mooney DJ. Highly porous polymer matrices as a three-dimensional culture system for hepatocytes. Cell Transplant 1997;6(5):463-8.

[31] Kang X, Xie Y, Kniss DA. Adipose tissue model using three-dimensional cultivation of preadipocytes seeded onto fibrous polymer scaffolds. Tissue Eng 2005;11(3-4):458-68.

[32] Tognana E, Borrione A, De Luca C, Pavesio A, Hyalograft C. hyaluronan-based scaffolds in tissue-engineered cartilage. Cells Tissues Organs 2007; 186(2):97-103.

[33] Hollander AP, Dickinson SC, Sims TJ, Brun P, Cortivo R, Kon E, et al. Maturation of tissue engineered cartilage implanted in injured and osteoarthritic human knees. Tissue Eng 2006;12(7):1787-98. 
[34] Nehrer S, Domayer S, Dorotka R, Schatz K, Bindreiter U, Kotz R. Three-year clinical outcome after chondrocyte transplantation using a hyaluronan matrix for cartilage repair. Eur J Radiol 2006;57(1):3-8.

[35] Laurent TC, Laurent UB, Fraser JR. Functions of hyaluronan. Ann Rheum Dis 1995;54(5):429-32.

[36] Butler JE, Hammond TH, Gray SD. Gender-related differences of hyaluronic acid distribution in the human vocal fold. Laryngoscope 2001;111(5):907-11.

[37] Evered D, Whelan J. Functions of proteoglycans. New York, NY: Wiley; 1986.

[38] Bouloumié A, Lolmède K, Sengenès C, Galitzky J, Lafontan M. Angiogenesis in adipose tissue. Ann Endocrinol 2002;63(2):91-5. Cahier 1.
[39] Deed R, Rooney P, Kumar P, Norton JD, Smith J, Freemont AJ, et al. Early-response gene signalling is induced by angiogenic oligosaccharides of hyaluronan in endothelial cells: inhibition by non-angiogenic, high-molecular-weight hyaluronan. Int J Cancer 1997;71(2):251-6.

[40] von Heimburg D, Hemmrich K, Zachariah S, Staiger H, Pallua N. Oxygen consumption in undifferentiated versus differentiated adipogenic mesenchymal precursor cells. Respir Physiol Neurobiol 2005;146(2-3):107-16.

[41] Kawaguchi N, Toriyama K, Nicodemou-Lena E, Inou K, Torii S, Kitagawa Y. De novo adipogenesis in mice at the site of injection of basement membrane and basic fibroblast growth factor. Proc Natl Acad Sci U S A 1998;95(3):1062-6. 